\title{
POSTULATION OF THE POSITION OF TRANSVERSE AXIS OF TEMPOROMANDIBULAR JOINT FROM CONDYLAR AND GONIAL DISPLACEMENTS
}

\author{
Sidharth Sankar Maharana1, Gopichand V. V. Patnaik2, Purna Chandra Maharana ${ }^{3}$ \\ 1Ph.D Research Scholar, Department of Anatomy, MMIMSR, Mullana-Ambala, Haryana. \\ 2 Professor, Department of Anatomy, MMIMSR, Mullana-Ambala, Haryana. \\ ${ }^{3}$ Professor and HOD, Department of Anatomy, GVPIHC and MT, Visakhapatnam, Andhra Pradesh.
}

\section{ABSTRACT}

\section{BACKGROUND}

The position of axis of temporomandibular joint on the ramus of mandible is controversial as reported earlier by many authors, but important for its necessity in clinical application, i.e. planting of mandibular prosthesis. Customarily, this hinge axis is presumed to be placed at the base of the lingular or lower attachment of sphenomandibular ligament, as it becomes taut when mouth is fully opened. As regard to the closing and opening of jaw, the mandible rotates around two hinge axes. The terminal hinge axis passing through the condyles mediolaterally and transverse axis passing at some point through the ramus.

\section{MATERIALS AND METHODS}

The present study was conducted on 1200 subjects (600 males and 600 females) of three states (Haryana, Himachal Pradesh and Odisha) belong to the age group of 18 - 25 years. Two parameters condylar protrusion or displacement (Cy. Disp.) and gonial retrusion or displacement (Go. Disp.) were selected including Condylar Gonion Displacement Index (CGDI) derived from two anthropometric measurements Nasion Condylon (Na-Cy) and Nasion Gonion (Na-Go) with the mouth closed and wide open by using sliding caliper.

\section{RESULTS}

The mean condylar displacement (Cy. Disp.) and gonial displacement (Go. Disp.) on total population being $7.41 \mathrm{~mm}$ and $16.77 \mathrm{~mm}$ respectively and the Condylon Gonion Displacement Index (CGDI) was 49.89.

\section{CONCLUSION}

As the Go. Disp. is approximately twice of the Cy. Disp. and the mean CGDI 49.89, the transverse axis on the ramus is being postulated to be present on the ramus nearer at the junction between upper one-fourth and lower three-fourth in an average.

\section{KEYWORDS}

Temporomandibular Joint (TMJ), Condylon (Cy), Condylar Protrusion (Cy. Disp.), Gonion (Go), Gonial Retrusion (Go. Disp.), Condylar-Gonial Displacement Index (CGDI), Midramus Point (MRP), Terminal Hinge Axis (THA) and Transverse Axis of Ramus (TAR).

HOW TO CITE THIS ARTICLE: Maharana SS, Patnaik GVV, Maharana PC. Postulation of the position of transverse axis of temporomandibular joint from condylar and gonial displacements. J. Evolution Med. Dent. Sci. 2017;6(37):3030-3033, D0I: $10.14260 /$ Jemds/2017/653

\section{BACKGROUND}

Although, the temporomandibular joint cannot function entirely independently of each other, they also rarely function with identical concurrent movement. ${ }^{1}$ The mandibular movements occur as a complex series of interrelated three dimensional rotational and translational activities in the inferior and superior compartments of the temporomandibular joint respectively, which is extremely difficult to appreciate and visualise. ${ }^{2}$

The typical hinge axis movement can occur when the condyles are stabilised in their most superior position in the articular fossa, which called the terminal hinge position or Centric Relation (CR) position.

Financial or Other, Competing Interest: None.

Submission 24-03-2017, Peer Review 26-04-2017,

Acceptance 02-05-2017, Published 08-05-2017.

Corresponding Author:

Sidharth Sankar Maharana,

Ph.D Research Scholar,

MMIMSR, Mullana-Ambala-133207,

Haryana, India.

E-mail: siddharth.maharana@gmail.com

DOI: $10.14260 /$ jemds $/ 2017 / 653$ plane around the Terminal Hinge Axis (THA) passing through the two (medial and lateral) poles of both condyles and mouth is opened up to $20-25 \mathrm{~mm}$ for normal talking and respiration without translation in the upper compartment of temporomandibular joint. This is initial or first stage of hinging movement that occurs during opening of the mouth with lowering of the mandible.

In the second stage hinging movement for further opening of mouth up to $40-60 \mathrm{~mm}$ results in an anteroinferior translation of the condyles down to the articular eminence around a second hinge axis passing somewhere through the rami with the postero-superior gonial displacement. The exact location of the second or lower transverse or hinge axis is not yet ascertained till date, but likely to be the site of lower attachment of the sphenomandibular ligament or mandibular foramina or base of lingula. . $^{3-5}$

\section{MATERIALS AND METHODS}

The study was carried out on 1200 subjects ( 600 males and 600 females) of 18 - 25 years' age group at three places Haryana, Himachal Pradesh and Odisha in India after getting 
clearance from the Institutional Ethical Committee and screened out basing on appropriate inclusion and exclusion criteria. All were found to be apparently healthy with normal masticatory function without any craniofacial deformity and trauma.

Three anatomical bony landmarks- Nasion ( $\mathrm{Na}$ ), Condylon (Cy) and Gonion (Go) were selected and two anthropometric measurements (Na-Cy and Na-Go) taken with the mouth closed (in centric relation (CR) position of the temporomandibular joints) and wide open with the help of the sliding caliper and the subject sitting on the chair in relaxed state and head in the anatomical position-

- Two measurements with the mouth closed- (Na-Cy) ${ }_{1}$ and (Na-Go) 1 [Fig. 1a].

- Two measurements with the mouth wide open- (Na-Cy) 2 and (Na-Go) 2 [Fig. 1b].

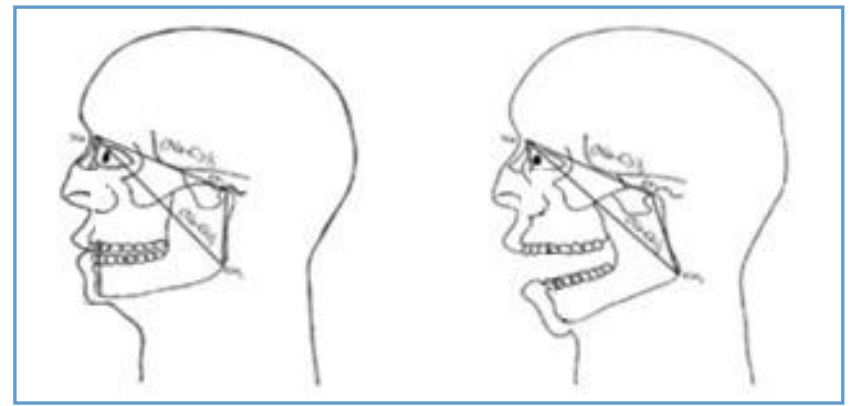

Figure 1a

Figure 1b

Figure 1. Showing two measurements (Na-Cy) and (Na-Go) during mouth closed (Fig. 1a) and wide open (Fig. 1b).

Two parameters were derived from these measurements, as the difference between the two states of mouth.

Condylar protrusion or displacement $(\mathrm{Cy}$. Disp. $)=(\mathrm{Na}-$ $\mathrm{Cy})_{1}-(\mathrm{Na}-\mathrm{Cy})_{2}$

Gonial retrusion or displacement (Go. Disp. $)=(\mathrm{Na}-\mathrm{Go})_{2}-$ (Na- Go) 1

The Condylon Gonion Displacement Index (CGDI) was calculated by using the formula as detailed below.

CGDI= Cy. Disp./Go. Disp. X100

\section{Statistical Analysis}

Statistical analysis was performed using SPSS version 20 software. All the parameters were calculated by descriptive statistics and Karl Pearson correlation coefficient (r). In all statistical analyses, a significant level of $p<0.05$ was used.

\section{RESULTS}

On full opening of the mouth, the mean Cy. Disp. irrespective of sides and sexes on total population $(\mathrm{N}=2400)$ is $7.41 \mathrm{~mm}$. In 1394 (58.08\%) cases, the Cy. Disp. range is $5-9.99 \mathrm{~mm}$, but in high percentage of cases i.e. 1908 (79.5\%) it is 5 $14.99 \mathrm{~mm}$. On the right side ( $\mathrm{N}=1200)$, the mean Cy. Disp. is $7.39 \mathrm{~mm}$ and in $963(80.25 \%)$ cases the range is $5-14.99$ $\mathrm{mm}$. On the left side $(\mathrm{N}=1200)$, the mean value is $7.44 \mathrm{~mm}$ and the range is $5-14.99 \mathrm{~mm}$ in 945 (78.75\%) (Table 1 and Fig. 2).

The Go. Disp. on total study population $(\mathrm{N}=2400)$ shows the mean value of $16.77 \mathrm{~mm}$ and in $1435(59.75 \%)$ cases the range $10-19.99 \mathrm{~mm}$ and in $1866(77.75 \%)$ it is $10-24 \mathrm{~mm}$. On the right side $(\mathrm{N}=2400)$, the mean Go. Disp. is $16.07 \mathrm{~mm}$ and in $940(78.25 \%)$ cases the range is $10-24.99 \mathrm{~mm}$. On the left side $(\mathrm{N}=1200)$ the mean Go. Disp. is $16.83 \mathrm{~mm}$ and in $926(77.17 \%)$ cases the range is $10-24.99 \mathrm{~mm}$ (Table 2 and Fig. 3).

The CGDI on total population $(\mathrm{N}=2400)$ shows the mean value of 49.89 and the range 10 - 39.99 in $984(41 \%)$ and 40 79.99 in $1109(46.21 \%)$ cases. On the right side $(\mathrm{N}=1200)$ the mean CGDI is 49.97 and in 505 (42.08\%) cases the range is $10-39.99$ and in 571 (47.58\%) cases $40-79.99$. On the left side $(\mathrm{N}=1200)$ the mean CGDI is 49.81 and the range 10 39.99 in $505(42.08 \%)$ and $40-79.99$ in 538 (44.83\%) cases (Table 3 and Fig. 4).

In males $(\mathrm{N}=1200)$ the mean CGDI is 46.46 and the range 10 - 39.99 in 583 (48.58\%) and 40 - 79.99 in 482 (40.17\%) cases. On the right side ( $\mathrm{N}=600)$, the mean CGDI is 46.14 and the range $10-39.99$ in 299 (49.83\%) and $40-79.99$ in 236 $(39.33 \%)$ cases. On the left side $(\mathrm{N}=600)$ the mean CGDI is 46.78 and the range is $10-39.99$ in $284(47.33 \%)$ and $40-$ 79.99 in 246 (41\%) cases (Table 4).

In females $(\mathrm{N}=1200)$ the mean CGDI is 53.33 and the range is $10-39.99$ in 401 (33.41\%) and $40-79.99$ in 627 $(52.25 \%)$ cases. On the right side $(\mathrm{N}=600)$ the mean CGDI is 53.80 and the range is $10-39.99$ in $180(30 \%)$ and $40-79.99$ in $335(55.83 \%)$ cases. On the left side $(\mathrm{N}=600)$ the mean CGDI is 52.85 and the range is $10-39.99$ in 221 (36.83\%) and 40 - 79.99 in 292 (48.67\%) cases (Table 5).

Statistically analysed that Cy. Disp. with Go. Disp. shows positive correlation and significant on total population and both sides. The similar positive correlation and statistical significance are also seen in Cy. Disp. with CGDI. However, correlation of Go. Disp. with CGDI shows negative correlation but statistically significant (Table 6).

\begin{tabular}{|c|c|c|c|}
\hline Parameter (N) & Mean $\mathbf{\text { SD }}$ & $\begin{array}{c}\text { No. of Cases } \\
\text { (\%) }\end{array}$ & Range \\
\hline $\begin{array}{c}\text { Cy. Disp (Total } \\
\text { population) (2400) }\end{array}$ & $7.41 \pm 2.80$ & $\begin{array}{c}1394(58.08) \\
1908(79.5)\end{array}$ & $\begin{array}{c}5-9.99 \\
5-14.99\end{array}$ \\
\hline Cy. Disp. Rt (1200) & $7.39 \pm 2.74$ & $963(80.25)$ & $5-14.99$ \\
\hline Cy. Disp. Lt (1200) & $7.44 \pm 2.86$ & $945(78.75)$ & $5-14.99$ \\
\hline \multicolumn{3}{|c|}{ Table 1. Mean and Frequency of } \\
Condylar Displacement (Cy. Disp) \\
\hline
\end{tabular}

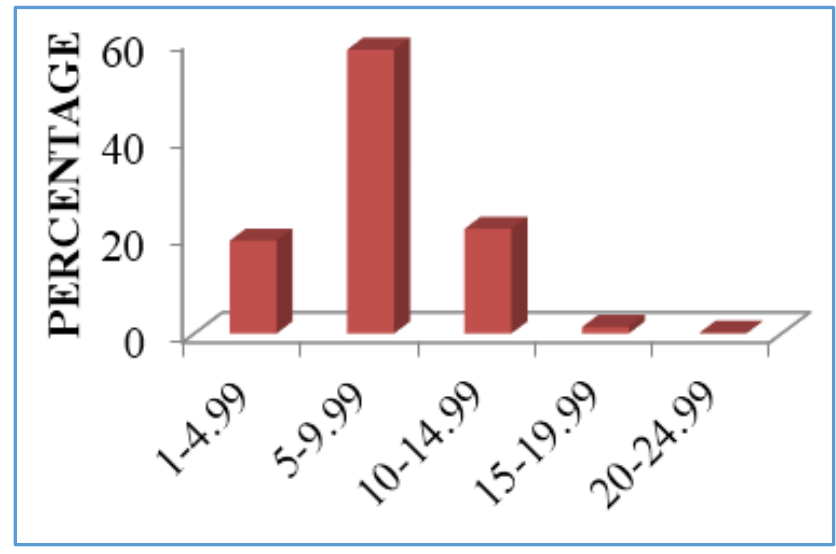

Figure 2. Distribution of Cy. Disp in Total Population 


\begin{tabular}{|c|c|c|c|}
\hline Parameter (N) & Mean \pm SD & $\begin{array}{c}\text { No. of Cases } \\
\text { (\%) }\end{array}$ & Range \\
\hline $\begin{array}{c}\text { Go. Disp (Total } \\
\text { Population) (2400) }\end{array}$ & $16.77 \pm 6.08$ & $\begin{array}{c}1435(59.75) \\
1866(77.75)\end{array}$ & $10-19.99$ \\
$10-24.99$ \\
\hline Go. Disp. Rt & $16.07 \pm 6.06$ & $940(78.25)$ & $10-24.99$ \\
\hline Go. Disp. Lt & $16.83 \pm 6.10$ & $926(77.17)$ & $10-24.99$ \\
\hline \multicolumn{3}{|c|}{ Table 2. Mean and Frequency of } \\
Gonial Displacement (Go. Disp). \\
\hline
\end{tabular}

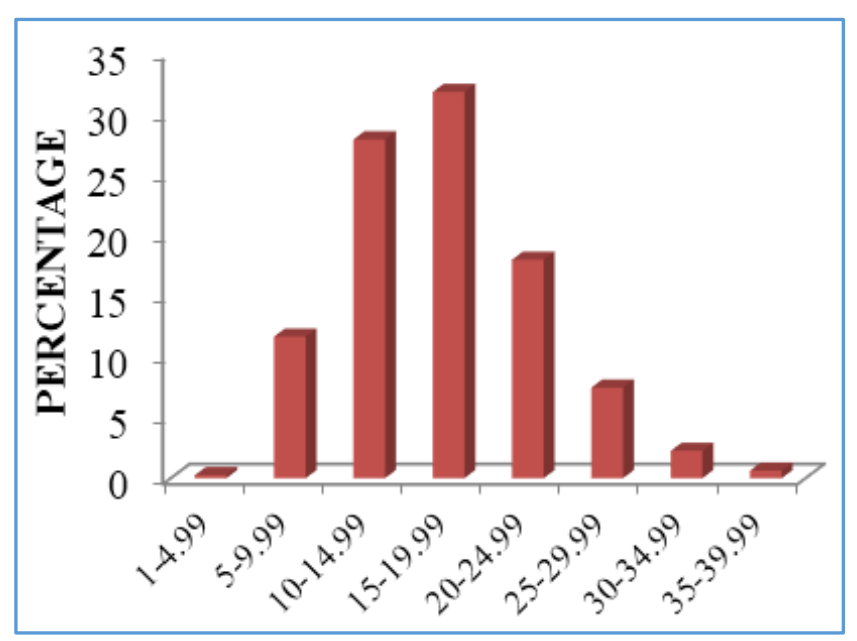

\begin{tabular}{|l|l|l|l|}
\hline CGDI. Lt (1200) & $49.81 \pm 25.91$ & $505(42.08)$ & $10-39.99$ \\
& $538(44.83)$ & $40-79.99$ \\
\hline
\end{tabular}

Table 3. Mean and Frequency of Condylon Gonion Displacement Index (CGDI)

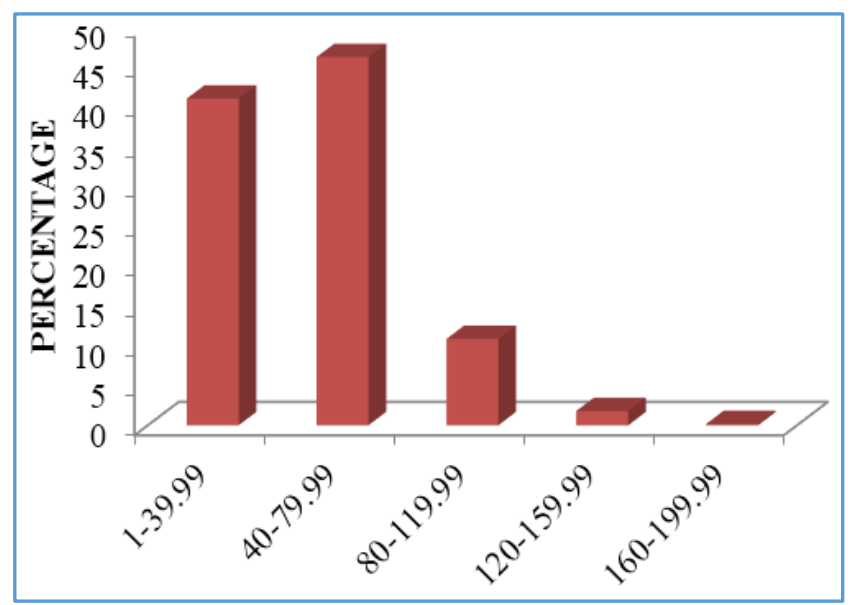

Figure 4. Distribution of CGDI in Total Population

\begin{tabular}{|c|c|c|c|}
\hline In Males CGDI (N) & Mean \pm SD & $\begin{array}{c}\text { No. of Cases } \\
\text { (\%) }\end{array}$ & Range \\
\hline CGDI. Rt (600) & $46.14 \pm 23.96$ & $\begin{array}{c}299(49.83) \\
236(39.33)\end{array}$ & $\begin{array}{c}10-39.99 \\
40-79.99\end{array}$ \\
\hline CGDI. Lt (600) & $46.78 \pm 25.47$ & $\begin{array}{c}284(47.33) \\
246(41)\end{array}$ & $\begin{array}{c}10-39.99 \\
40-79.99\end{array}$ \\
\hline $\begin{array}{c}\text { CGDI (Total } \\
\text { Population) (1200) }\end{array}$ & $46.46 \pm 24.72$ & $\begin{array}{c}583(48.58) \\
482(40.17)\end{array}$ & $\begin{array}{c}10-39.99 \\
40-79.99\end{array}$ \\
\hline \multicolumn{2}{|c|}{ Table 4. Mean and Frequency of Condylon Gonion } \\
Displacement Index (CGDI) in Males \\
\hline
\end{tabular}
Displacement Index (CGDI) in Males

\begin{tabular}{|c|c|c|c|}
\hline Parameter (N) & Mean \pm SD & $\begin{array}{c}\text { No. of Cases } \\
\text { (\%) }\end{array}$ & Range \\
\hline $\begin{array}{c}\text { CGDI (Total } \\
\text { Population) } \\
(2400)\end{array}$ & $49.89 \pm 25.57$ & $\begin{array}{c}984(41) \\
1109(46.21)\end{array}$ & $\begin{array}{c}10-39.99 \\
40-79.99\end{array}$ \\
\hline CGDI. Rt (1200) & $49.97 \pm 25.23$ & $\begin{array}{c}505(42.08) \\
571(47.58)\end{array}$ & $\begin{array}{c}10-39.99 \\
40-79.99\end{array}$ \\
\hline
\end{tabular}

\begin{tabular}{|c|c|c|c|}
\hline In Females CGDI (N) & Mean \pm SD & No. of Cases (\%) & Range \\
\hline \multirow{2}{*}{ CGDI. Rt (600) } & \multirow{2}{*}{$53.80 \pm 25.90$} & $180(30)$ & $10-39.99$ \\
& & $335(55.83)$ & $10-79.99$ \\
\hline \multirow{2}{*}{ CGDI. Lt (600) } & \multirow{2}{*}{$52.85 \pm 26.02$} & $221(36.83)$ & $40-79.99$ \\
\hline \multirow{2}{*}{ CGDI (Total Population) (1200) } & \multirow{2}{*}{$53.32 \pm 25.96$} & $401(38.67)$ & $10-39.99$ \\
\hline \multicolumn{2}{|c|}{ Table 5. Mean and Frequency of Condylon Gonion Displacement Index (CGDI) in Females }
\end{tabular}

\begin{tabular}{|c|c|c|c|c|c|c|c|}
\hline Parameter & & GO. DISP. R & GO. DISP. L & GO. DISP. RL & CGDI. R & CGDI. L & CGDI. RL \\
\hline \multirow{3}{*}{ CY. DISP. R } & $\mathrm{r}$ & $0.073^{*}$ & $\mathrm{x}$ & $\mathrm{x}$ & $0.622^{*}$ & $\mathrm{x}$ & $\mathrm{x}$ \\
\hline & sig & 0.012 & $\mathrm{x}$ & $\mathrm{x}$ & 0.000 & $\mathrm{x}$ & $\mathrm{x}$ \\
\hline & $\mathrm{N}$ & 1200 & $\mathrm{x}$ & $\mathrm{x}$ & 1200 & $\mathrm{x}$ & $\mathrm{x}$ \\
\hline \multirow{3}{*}{ CY. DISP. L } & $\mathrm{r}$ & $\mathrm{x}$ & $0.103^{*}$ & $\mathrm{x}$ & $\mathrm{x}$ & $0.614^{*}$ & $\mathrm{x}$ \\
\hline & sig & $\mathrm{x}$ & 0.000 & $\mathrm{x}$ & $\mathrm{x}$ & 0.000 & $\mathrm{x}$ \\
\hline & $\mathrm{N}$ & $\mathrm{x}$ & 1200 & $\mathrm{x}$ & $\mathrm{x}$ & 1200 & $\mathrm{x}$ \\
\hline \multirow{3}{*}{ CY. DISP. RL } & $\mathrm{r}$ & $\mathrm{x}$ & $\mathrm{x}$ & $0.103^{*}$ & $\mathrm{x}$ & $\mathrm{x}$ & $0.618^{*}$ \\
\hline & sig & $\mathrm{x}$ & $\mathrm{x}$ & 0.000 & $\mathrm{x}$ & $\mathrm{x}$ & 0.000 \\
\hline & $\mathrm{N}$ & $\mathrm{x}$ & $\mathrm{x}$ & 2400 & $\mathrm{x}$ & $\mathrm{x}$ & 2400 \\
\hline \multirow{3}{*}{ GO. DISP. R } & $\mathrm{r}$ & $\mathrm{x}$ & $\mathrm{x}$ & $\mathrm{x}$ & $-0.626^{*}$ & $\mathrm{x}$ & $\mathrm{x}$ \\
\hline & sig & $\mathrm{x}$ & $\mathrm{x}$ & $\mathrm{x}$ & 0.000 & $\mathrm{x}$ & $\mathrm{x}$ \\
\hline & $\mathrm{N}$ & $\mathrm{x}$ & $\mathrm{x}$ & $\mathrm{x}$ & 1200 & $\mathrm{x}$ & $\mathrm{x}$ \\
\hline \multirow{3}{*}{ GO. DISP. L } & $\mathrm{r}$ & $\mathrm{x}$ & $\mathrm{x}$ & $\mathrm{x}$ & $\mathrm{x}$ & $-0.600^{*}$ & $\mathrm{x}$ \\
\hline & sig & $\mathrm{x}$ & $\mathrm{x}$ & $\mathrm{x}$ & $\mathrm{x}$ & 0.000 & $\mathrm{x}$ \\
\hline & $\mathrm{N}$ & $\mathrm{x}$ & $\mathrm{x}$ & $\mathrm{x}$ & $\mathrm{x}$ & 1200 & $\mathrm{x}$ \\
\hline \multirow{3}{*}{ GO. DISP. RL } & $r$ & $\mathrm{x}$ & $\mathrm{x}$ & $\mathrm{x}$ & $\mathrm{x}$ & $\mathrm{x}$ & $-0.613^{*}$ \\
\hline & sig & $\mathrm{x}$ & $\mathrm{x}$ & $\mathrm{x}$ & $\mathrm{x}$ & $\mathrm{x}$ & 0.000 \\
\hline & $\mathrm{N}$ & $\mathrm{x}$ & $\mathrm{x}$ & $\mathrm{x}$ & $\mathrm{x}$ & $\mathrm{x}$ & 2400 \\
\hline
\end{tabular}




\section{DISCUSSION}

The temporomandibular joint of both sides are not independent of each other in function and peculiar type of synovial joint as the mouth opens and closes with the rotation of mandible around the terminal hinge axis of lower compartment as well as the transverse axis of the ramus as a result of the translation in the upper compartment of the joint with the protrusion of condyles and the retrusion of the gonion. ${ }^{6}$

On total study population, the mean (Cy. Disp.) is $7.41 \mathrm{~mm}$ and Go. Disp. is $16.77 \mathrm{~mm}$, which is evident that Go. Disp. is nearly the twice of the Cy. Disp. and nearly about in $60 \%$ cases the Cy. Disp. range is $5-9.99 \mathrm{~mm}$ and Go. Disp range 10 - $19.99 \mathrm{~mm}$; in $80 \%$ of cases Cy. Disp. range is $5-14.99 \mathrm{~mm}$ and Go. Disp. range $10-24.99 \mathrm{~mm}$ which also shows that Go. Disp. is twice of the Cy. Disp. It is to be presumed that the second hinge axis on the ramus (TAR) situated nearer at the midway between condylon and Midramus Point (MRP). No visible difference is marked between right and left sides as regard to mean value and ranges of Cy. Disp. and Go. Disp., which suggests the bilateral symmetry maintained during closing and opening the jaw and also supported by J. Chen (1993). ${ }^{6}$

When the percentage of the ratio of Cy. Disp. with the Go. Disp. as Condylar Gonial Displacement Index (CGDI) is taken into account, it is seen that the mean value is nearly 50 on total population as well as on both sides; the ranges 10 39.99 in $42 \%$ cases and $40-79.99$ in $45 \%-47 \%$ cases are also marked almost same on total population as well as on both right and left sides, which suggest the bilateral symmetry is maintained during closing and opening of the jaw and the position of the Transverse Axis on the Ramus (TAR) nearly at the midway between the condylon and the Midramus Point (MRP).

When the CGDI of males have been compared with that of the females, it reveals that the Transverse Axis on the Ramus (TAR) is presumed to be situated a little above the midway between the condylon and the Midramus Point (MRP), i.e. towards condylon as the mean value of CGDI is 46.14 and in female it is situated a little below the midway between the condylon and Midramus Point (MRP), i.e. towards MRP as the mean value of CGDI is 53.33. In both males and females bilateral symmetry has been marked during the movement of the jaw, as no visible difference is seen in the mean values and ranges between right and left sides.

\section{CONCLUSION}

A very little or no visible difference is marked as regard to Cy. Disp, Go. Disp and CGDI both in mean values and ranges between right and left sides, suggesting bilateral symmetry during opening of jaw. This finding of the present study is supported by that of the report of J. Chen (1993). ${ }^{6}$
The Transverse Axis of the Ramus (TAR) is presumed to be present somewhere nearer at the junction between the upper one-fourth and lower three-fourth of the ramus of the mandible as evident from the mean value of Cy. Disp. (7.41 $\mathrm{mm}$ ), Go. Disp. (16.77 mm) and also CGDI (49.89), which is also supported by the findings of L. Patnaik et al (2004) and according to them this second hinge axis on the ramus is situated above the Mid Ramus Point (MRP) in $96.66 \%$ cases, but contradicts with the statements of many previous authors. ${ }^{7}$

A minor sexual dimorphism is seen in the position of this Transverse Axis of the Ramus (TAR), as it is situated a little above the junction between upper one-fourth and lower three-fourths of the ramus (i.e. towards condylon) in males, but in females it is placed a little below this junction (towards MRP).

The findings of the present study have been statistically analysed and found significant; and can be helpful in clinical applications (medical and dental surgery) particularly for planting mandibular prosthesis in fractured jaw.

\section{ACKNOWLEDGEMENT}

I sincerely thank Dr. Y. Roja Ramani (Assistant Professor), Dr. Abinash Panda (Assistant Professor) Department of Pharmacology, MKCG Medical College, Berhampur, Odisha for their valuable help in statistically analysing the data in the present study.

\section{REFERENCES}

[1] Okeson JP. Functional anatomy and biomechanics of the masticatory system. In: Management of temporomandibular disorders and occlusion. 6th edn. Mosby Elsevier 2008:p. 7.

[2] Lindauer SJ, Sabol G, Isaacaso RJ, et al. Condylar movement and mandibular rotation during jaw opening. Am J Orthod Dentofacial Orthop 1995;107(6):573-7.

[3] Sharma RN. Disorders of the temporomandibular joint. In: Sinha RN, ed. A textbook of plastic surgery in the topics. Orient Longman 1976.

[4] Standring S. Gray's anatomy. 38th edn. London: Churchill Livingstone 1999.

[5] Last RJ. Anatomy regional and applied. $6^{\text {th }}$ edn. Edinburgh: Churchill Livingstone 1978.

[6] Chen J, Buckwalter K. Displacement analysis of temporomandibular condyle from magnetic resonance images. J Biomech 1993;26(12):1455-62.

[7] Pattnaik L, Maharana PC. Determination of the transverse axis of temporomandibular joint by using a new method. Anatomical science International, Blackwell publishing. $16^{\text {th }}$ International congress of the IFAA proceedings 2004;79:3-051. 